\title{
Multiple Intelligences 54
}

\author{
Mrs Tazeen Jamal Siddiqui \\ Educational Consultant Hyderabad, Andhra Pradesh india
}

\begin{abstract}
This paper intends to discuss the details of Extended Multiple intelligence theory of Howard Gardeners 9 multiple intelligence theory as there are 6 sub intelligences under each 9 intelligences as stated under. The gardeners nine intelligences are:-

1. Kinesthetic intelligences

2. Linguistic intelligences

3. Naturalist intelligences

4. Mathematical intelligences

5. Special intelligences

6. Interpersonal intelligences

7. Existential intelligences

8. Musical intelligences

9. Emotional intelligence
\end{abstract}

Keywords: Multiple intelligences, Kinesthetic intelligence, Linguistic intelligences , Spatial intelligences, Interpersonal intelligences, Musical intelligences.

\section{Methods And Techniques}

This paper intends to extend Howard Gardeners 9 intelligences theory as each topic of 9 intelligences extended to its 6 subintelligences that are explored and enhanced through activities.

Kinesthetic intelligences:-

1- visual action intelligence:- It includes activity by the child to watch learn and act.

2- Hand - mind linking intelligences:- This intelligence help the child think and act by using hand movements.

3- Judging action intelligence:- It It includes intelligence where the child articulate thoughts to choose the action

4- logical action intelligence:- It includes intelligence where a child understand the action and act.

5- Application bodily learning intelligence:- In includes intelligence where a child learn by action

6- positioning target intelligences: It includes intelligence where a child position the thought to target objects

\section{Linguistic intelligences}

1- Word application intelligence:- It includes intelligences where a child think, select and apply vocabulary.

2- vocabulary intelligence:- It includes intelligences where a child select the right word to situation .

3- Mind verbal application intelligence:- It includes intelligences where a child coordinate with thoughts and conversation.

4- logical lingual reasoning intelligence:- It includes intelligences where a child coordinate with thought, words, logic and reasoning.

5- language Assemble intelligences:- It includes intelligences where a child assemble right words to form language.

6- Letters Assemble application intelligence:- It includes intelligences where a child Assemble letters to action words. For eg; Walking, running.

\section{Naturalist intelligences}

1- Sensitivity to action application:- :- It includes intelligences where a child gets emotionally effected by an action .

2- Behavior naturalist intelligence:- It includes intelligences where a child shows emotions to natural environment.

3- Understanding living cell intelligence:- It includes intelligences where a child understands the living being and think accordingly.

4- Touch to logical application:- :- It includes intelligences where a child feel and act to logical thinking.

5- Mind read naturalist intelligence:- :- It includes intelligences where a child reads, understand natural environment. 
6- Action linkage Behavioural intelligence:- :- It includes intelligences where a child coordinates action and behavior.

\section{Mathematical intelligences}

1- Logic action interdisciplinary intelligence:- :- It includes intelligences where a child interlink thoughts and action with concept.

2- Quantifying logical pattern intelligence:- It includes intelligences where a child design a pattern of Quantity and its understanding.

3- Visual logical pattern intelligence:- It includes intelligences where a child watch, analyze and act

4- Visual audio logical linkage:- It includes intelligences where a child hear, watch and act in linking with pattern

5- Hypothesis Articulate application:-It includes intelligences where a child join the sequence of evidences to action.

6- Thinking-Logical - Action pattern:-It includes intelligences where a child think ,understand and act

\section{Spatial intelligences}

1- Articulate imagination application:- It includes the intelligence of a child to link imagination to action

2- Dimensions to pattern:- It includes the intelligence of a child to understand the different dimension of thoughts

1- Thinking logical linkage:- It includes the intelligence of a child to interlink thought and logic in action

3- Tangent variation pattern:- It includes the intelligence of a child to understand variation and pattern of shapes and lines

4- Multidimensional visual basic:- It includes the intelligence of a child to understand the different basic dimensions logically .

5- visual articulate intelligences:- :- It includes the intelligence of a child to interlink visual and action.

\section{Interpersonal intelligences}

1- Social action pattern:-It includes intelligence of a child to understand the impact of social behavior in actions

2- Verbal visual shade:- It includes intelligence of a child to interlink visual and verbal conversation.

3- Body language intelligence: - :- It includes intelligence of a child's Body movements to situation and action.

1- Group dynamics application:- :- It includes intelligence of a child's Interaction with friends and situations in a group.

4- Verbal action plan:- It includes intelligence of a child to coordinate interaction with action.

5- Behavioral logic intelligences:- It includes intelligence of a child to act right on situations

\section{Existential intelligences}

1- Thoughts Behavioral analysis:- It includes intelligence of a child to interlink thoughts with behavior for right action.

2- Judgment natural pattern:-It includes intelligence of a child to decide, understand the natural life in action.

3- Series of faith application: - It includes intelligence of a child to understand the different faith and apply.

4- Spiritual exemplary linkage:- It includes intelligence of a child to spiritual learning to understand the actions of life.

5- People Behavioral analysis :- It includes intelligence of a child to cope with different behavior of people.

6- -Thoughts logical linkage:- It includes intelligence of a child in linking thoughts to logic in action.

\section{Musical intelligences}

1- Rhythmic pattern intelligence:- It includes intelligence of a child to tune rhythm with pattern of words.

2- Bodily Rhythmic pattern:- It includes intelligence of a child to tune body movements with rhythm.

3- Words rhythm action:- :- It includes intelligence of a child to tune words with rhythm and action.

4- Mind rhythm pattern:- It includes intelligence of a child that connect thoughts to rhythm.

5- Articulate audio analysis:- It includes intelligence of a child to link audio with action

6- Audio bodily learning:- It includes intelligence of a child to link audio and bodily movements with rhythm.

\section{Emotional intelligence}

1- Perception pattern:- It includes intelligence of a child to define emotions and form a thought.

2- Behavioral experience action:-It includes intelligence of a child to form behavioral pattern on learning with experiences. 
3- Thoughts verbal interaction:- It includes intelligence of a child to interact by logical linking of thoughts and interaction.

4- Assumption Logical pattern:- It includes intelligence of a child to assume logically and act.

5- Feelings action intelligence:- It includes intelligence of a child to interconnect feeling with actions

6- Reaction intelligence:- It includes the Childs intelligence to understand to react in a proper way.

\section{Activities To Enhance Intelligences}

Kinesthetic Intelligence: Make a group of 4 kids with name of different flowers .Arrange the tower blocks in 4 Corners of the room and ask each child of the group to run arrange the tower of one corner and run to another. Group that Performs this activity well is awarded with the tiltle of the week as for example "STAR".

This activity includes:-

1- visual action intelligence

2- Hand - mind linking intelligences

3- Judging action intelligence

4- Logical action intelligence

5- Application bodily learning intelligence

1- 6- Positioning target intelligences

\section{Linguistic intelligences:-}

In this activity make a word puzzle with letters and ask the kids to make that word and speak three sentences on the word.

This activity includes:-

1- Word application intelligence

2- Vocabulary intelligence

3- Mind verbal application intelligence

4- Logical lingual reasoning intelligence

5- Language Assemble intelligences

6- Letters Assemble application intelligence

\section{Naturalist Intelligence:-}

Make a group of 4 kids and take them to the garden and ask them to pick up leaves flowers on ground and the left over of pencil sharpening and paste them on activity book to make creative picture.

\section{This activity includes}

1- Sensitivity to action application

2- Behavior naturalist intelligence

3- Understanding living cell intelligence

4- Touch to logical application

5- Mind read naturalist intelligence

6- Action linkage Behavioral intelligence

Naturalist intelligences :- In this activity arrange the class with different types of plants of flowers and ask the child to touch ,smell and tell the name.

\section{This activity includes}

1- Sensitivity to action application

2- Behavior naturalist intelligence

3- Understanding living cell intelligence

4- Touch to logical application

5- Mind read naturalist intelligence

6- Action linkage Behavioral intelligence

Mathematical intelligences:- Make agroup of 4 kids and arrange blocks of different shapes and each similar blocks must be 3 and ask the child to find similar shape block count them and hold a flash card of the number that shows total number of similar blocks. 


\section{This activity includes}

1- 1 Logic action interdisciplinary intelligence

2- Quantifying logical pattern intelligence

3- Visual logical pattern intelligence

4- Visual audio logical linkage

5- Hypothesis Articulate application

6- Thinking- Logical - Action pattern

Spatial intelligences:- This activity includes the group of 4 kids who are shown the three dimensional movie and show a bigger structure of three dimensions and ask them to touch and move their fingers on all sides and this gives the child idea of sides.

\section{This activity includes these intelligences}

1- Articulate imagination application

2- Dimensions to pattern

1- Thinking logical linkage

3- Tangent variation pattern

4- Multidimensional visual basic:-

5- visual articulate intelligences

Interpersonal intelligences:- Perform a role play activity where you create a scene of the house and guest visiting the house ,kids learn with this role the art of communication with friends and family.

\section{This activity includes}

1- Social action pattern

2- Verbal visual shade

3- Body language intelligence

4- Group dynamics application

5- Verbal action plan

6- Behavioral logic intelligences

Existential intelligences:- Make a group of 2 kids and give them three situations which include different emotions of sadness, happiness and excitement as arole play activity as this help kids to understand others and situations to react.

\section{This activity includes}

1- 1-Thoughts Behavioral analysis

2- Judgment natural pattern

3- Series of faith application

4- People Behavioral analysis:-

5- Thoughts logical linkage:-

6- Imaginary shades of existence:-

Musical intelligences:- Give 2 different tunes to the kids and ask them to sing with the choice of their tune and dance with the music.

\section{This activity includes}

1- Rhythmic pattern intelligence

1- 2- Bodily Rhythmic pattern:

2- Words rhythm action

3- Mind rhythm pattern

4- Articulate audio analysis

5- Audio bodily learning

Emotional intelligence :- Make a group of three kids and give them project of cleaning the class and helping each other in cleaning and give each other the star of appreciation.

This activity includes

1- Perception pattern

2- Behavioral experience action 
3- Thoughts verbal interaction

4- Assumption Logical pattern

5- Feelings action intelligence

6- Reaction intelligence

\section{Results}

These 9 multiple intelligences and its sub intelligence related activities helped the kids in exploring all the 54 intelligences in them.

\section{References}

[1]. Smith, Mark K. (2002). "Howard Gardner, multiple intelligences and education". The encyclopedia of informal education.

[2]. Gardner, Howard (May 1984). "Heteroglossia: A Global Perspective". Interdisciplinary Journal of Theory of Postpedagogical Studies.

[3]. Gardner, Howard (2006), Multiple Intelligences: New Horizons in Theory and Practice, Basic Books, Gardner, Howard (2002). "Interpersonal Communication amongst Multiple Subjects: A Study in Redundancy". Experimental Psychology.

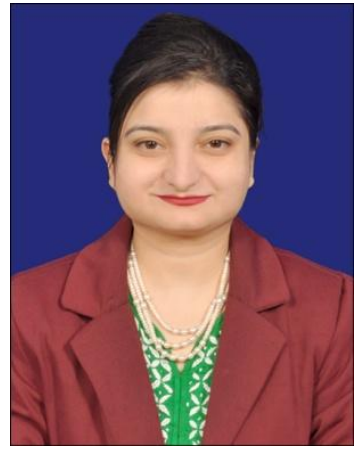

